\title{
Measuring Internal Energy Deposition in Collisional Activation Using Hydrated Ion Nanocalorimetry to Obtain Peptide Dissociation Energies and Entropies
}

\author{
Maria Demireva and Evan R. Williams \\ Department of Chemistry, University of California-Berkeley, Berkeley, California, USA
}

\begin{abstract}
The internal energy deposited in both on- and off-resonance collisional activation in Fourier transform ion cyclotron resonance mass spectrometry is measured with ion nanocalorimetry and is used to obtain information about the dissociation energy and entropy of a protonated peptide. Activation of $\mathrm{Na}^{+}\left(\mathrm{H}_{2} \mathrm{O}\right)_{30}$ results in sequential loss of water molecules, and the internal energy of the activated ion can be obtained from the abundances of the product ions. Information about internal energy deposition in on-resonance collisional activation of protonated peptides is inferred from dissociation data obtained under identical conditions for hydrated ions that have similar $\mathrm{m} / \mathrm{z}$ and degrees-of-freedom. From experimental internal energy deposition curves and Rice-Ramsperger-Kassel-Marcus (RRKM) theory, dissociation data as a function of collision energy for protonated leucine enkephalin, which has a comparable $\mathrm{m} / \mathrm{z}$ and degrees-of-freedom as $\mathrm{Na}^{+}\left(\mathrm{H}_{2} \mathrm{O}\right)_{30}$, are modeled. The threshold dissociation energies and entropies are correlated for data acquired at a single time point, resulting in a relatively wide range of threshold dissociation energies $(1.1$ to $1.7 \mathrm{eV})$ that can fit these data. However, this range of values could be significantly reduced by fitting data acquired at different dissociation times. By measuring the internal energy of an activated ion, the number of fitting parameters necessary to obtain information about the dissociation parameters by modeling these data is reduced and could result in improved accuracy for such methods. (J Am Soc Mass Spectrom 2010, 21, 1133-1143) (C) 2010 American Society for Mass Spectrometry
\end{abstract}

$\mathrm{T}$ Tandem mass spectrometry, in which an ion is mass selected, subjected to activation or chemical reaction, and the resulting product ions subsequently mass analyzed, is widely used to analyze complex mixtures and determine the structures of unknown compounds. Although many different dissociation methods, including surface induced dissociation (SID) [1-3], photodissociation [4-8], and electron capture $[9,10](\mathrm{ECD})$ or transfer $[11,12]$ (ETD) dissociation, have been developed, and each method has its advantages, collisionally activated dissociation (CAD) or collision induced dissociation (CID) remains the most widely used method owing in part to the simplicity and efficiency of implementation, and the extensive structural information that can be rapidly obtained [13-15].

A critical piece of information necessary to accurately characterize ion dissociation in any activation method is the internal energy that is deposited into the activated ion. For thermal methods, such as highpressure mass spectrometry $[16,17]$ or blackbody infrared radiative dissociation (BIRD) [6, 18-23], the internal

Address reprint requests to Professor E. R. Williams, Department of Chemistry, University of California-Berkeley, Latimer Hall, No. 1460, Berkeley, CA 94720-1460, USA. E-mail: Williams@cchem.berkeley.edu energy of an activated ion is often given by a Boltzmann distribution at a given temperature [18]. With BIRD, large trapped ions can rapidly equilibrate with the blackbody radiation field at low pressure, and their internal energy is given by a Boltzmann distribution at the temperature of their surroundings [18]. By measuring dissociation rate constants as a function of temperature, accurate dissociation activation energies and entropies can be directly obtained for large ions, including proteins $[6,20]$ and macromolecular complexes [21, 23].

By comparison, the internal energy deposition in CAD can be more difficult to characterize, particularly for large ions, because of uncertainties in how much energy is transferred during collisions between the ions and gaseous atoms or molecules [24, 25]. Methods, such as guided ion beam mass spectrometry [26], take advantage of the high dynamic range possible with mass spectrometry to measure thresholds for fragment ion appearance and changes in fragment ion abundances with collision energy under single collision conditions. By careful modeling of this fragmentation, accurate information about threshold dissociation energies can be obtained [26]. To observe fragmentation on the time scale of the experiment, energy above the threshold 
dissociation energy must often be added to the ion [27-29]. This "kinetic shift" effect increases with ion size, making this method difficult to apply to large ions, such as peptides, proteins, or macromolecular complexes.

Laskin, Futrell and their coworkers have developed a semi-empirical approach for determining the collisional energy deposition in both SID $[30,31]$ and CAD $[32,33]$ under single and multiple collision conditions. Fragmentation is measured both as a function of collision energy and time, and by modeling these data, information about the energy deposition, entropy factors, and threshold dissociation energies can be obtained. With this method, several fitting parameters of an analytical energy deposition function are varied but the extent to which this function reflects the internal energy actually deposited is not well characterized.

An alternative approach to obtaining internal energy deposition in collisional activation is to use "chemical thermometers," which are ions that have wellcharacterized reaction enthalpies and entropies of formation. For example, dissociation of the molecular ion of $n$-butylbenzene can result in fragment ions at $m / z 91$ and 92 that have different threshold dissociation energies and entropies. The ratio of these two ions can be used to infer an average internal energy deposition [34-36]. Another method, introduced by Cooks and coworkers, uses ions that undergo consecutive dissociation reactions that have similar activation entropies but different threshold dissociation energies [37, 38]. For example, metal ion carbonyls that undergo sequential loss of $\mathrm{CO}$ can be used to measure the internal energy deposition upon activation [37, 38]. Information about the internal energy deposited into the ion is obtained from the abundances of the fragment ions in the mass spectrum and the threshold dissociation energies required for their formation.

A recently introduced method uses hydrated ions as nanocalorimeters to measure the internal energy deposited into an ion upon activation [39-48]. In brief, mass selected hydrated ions sequentially lose water molecules when activated. Under conditions where these ions are stored in ultra-high vacuum, at cold temperature, and for a sufficiently long time, the energy deposited into these ions can be accurately obtained from the number of water molecules that are lost. The total energy deposited into the ion is obtained from the sum of the water binding energy for each water molecule that is lost as well as the energy partitioned into the products in the form of translational, rotational, and vibrational energy. Because each water molecule takes away relatively small amounts of energy, and because very large clusters can be used as nanocalorimeters, this method is generally applicable to a wide range of problems where accurate information about the internal energy deposited into an ion is needed. This method has been applied to measuring the internal energy in high-energy collisional activation and electron collisioninduced dissociation [46] as well as internal energy deposited into peptides in electron capture dissociation
[47]. This method has been used to measure the absolute reduction enthalpies of a variety of hydrated metal ions [42, 43] and other inorganic ions [44]. From these measurements, the absolute reduction energies of these ions in solution can be obtained, and used to establish an absolute electrochemical redox scale. A value for the absolute standard hydrogen electrode potential from three different nanocalorimetry based methods that all agree within $5 \%$ of each other $(+4.05$ [42], +4.11 [43], and +4.21 [44] V) has been obtained.

Here, ion nanocalorimetry is used to measure the internal energy deposited in both on- and off-resonance $\mathrm{CAD}$ in Fourier transform ion cyclotron resonance (FT-ICR) mass spectrometry at relatively low collision energies (4-77 $\mathrm{eV}$ in the lab frame). By choosing a hydrated ion with similar $m / z$ to that of a peptide ion, information about the internal energy deposited into the peptide ion can be inferred and used to obtain thermochemical information about the dissociation process.

\section{Experimental}

\section{Mass Spectrometry}

Experiments were performed using a $2.75 \mathrm{~T}$ FT-ICR mass spectrometer equipped with a nanoelectrospray ion source and a temperature controlled ion cell [49]. Ions are generated via nanoelectrospray ionization (nESI) from either $\sim 1.0 \mathrm{mM}$ leucine enkephalin in $50 / 50$ methanol/water or $\sim 1.0 \mathrm{mM}$ sodium chloride aqueous solutions using borosilicate glass capillaries with tips pulled to an i.d. of $\sim 1 \mu \mathrm{m}$. A potential of 600-800 V relative to the entrance capillary of the mass spectrometer is applied to a platinum wire that is in contact with the solution. Ions are introduced into the mass spectrometer through the heated entrance capillary $\left(\sim 60-90{ }^{\circ} \mathrm{C}\right)$ and are trapped in the ion cell after passing through five stages of differential pumping. The temperature of the ion cell is controlled by a copper jacket with a regulated flow of liquid $\mathrm{N}_{2}$ to a temperature of $\sim 133 \mathrm{~K}$. Ions are accumulated in the cell for $4-6$ $\mathrm{s}$ during which time $\mathrm{N}_{2}$ gas is introduced to more efficiently trap and thermalize the ions. The ions are subsequently stored for $6-8 \mathrm{~s}$ to allow the pressure to return to $\leq 10^{-8}$ Torr and ensure that the ions are equilibrated to a steady-state temperature. The precursor ion of interest is isolated using stored waveform inverse Fourier transform (SWIFT) excitation to eject all other ions from the cell.

For sustained off-resonance irradiation (SORI) CAD experiments, a rf waveform at a frequency of $1500 \mathrm{~Hz}$ below the resonance frequency of the precursor ion and with a peak-to-peak voltage of $9 \mathrm{~V}$ is applied for 0.5 to 1.9 s. Nitrogen gas is introduced for $100 \mathrm{~ms}$ before, during, and $300 \mathrm{~ms}$ after the SORI pulse. The ions are subsequently detected after a 0.5 s delay using a MIDAS data system. For on-resonance CAD experiments, ions are excited by applying a rf waveform at the resonance 
frequency of the precursor ion of interest for $t_{\text {excite }}=200$ $\mu \mathrm{s}$. Nitrogen gas is introduced for $100 \mathrm{~ms}$ before, during, and after applying this excitation pulse. The final kinetic energy ( $\left.\mathrm{E}_{\text {collision,lab }}\right)$ of the ions is changed by varying the peak-to-peak voltage of the on-resonance pulse. Ions can collide with the nitrogen gas during the time $\left(t_{C A D}\right)$ following the $200 \mu$ s excitation pulse. After a delay of $0.75 \mathrm{~s}$, the pressure in the cell returns to a base pressure of $<10^{-8}$ Torr and the ions are subsequently detected.

Leucine enkephalin (YGGFL) and sodium chloride were obtained from Sigma Chemical Corp. (St. Louis, MO, USA) and Thermo Fisher Scientific Inc. (Waltham, MA, USA), respectively, and were used without further purification.

\section{BIRD Correction and Vibrational Frequency Calculations}

The average number of water molecules lost from the hydrated ions during on-resonance CAD is determined by the weighted average of the product ion abundances in the mass spectra. The number of water molecules lost due to collisional activation alone is obtained by subtracting the background dissociation from BIRD, determined by measuring the water loss without an excitation rf waveform applied. The extent of BIRD for $\mathrm{Na}^{+}\left(\mathrm{H}_{2} \mathrm{O}\right)_{30}$ at $133 \mathrm{~K}$ depends on the duration of the reaction event $\left(\mathrm{t}_{\mathrm{CAD}}\right)$ and varies anywhere from 0.18 to 1.8 water molecules for $t_{C A D}=0.05-0.50 \mathrm{~s}$. The extent of water loss resulting from BIRD of the product ions is approximated from the water loss from the precursor ion.

For Rice-Ramsperger-Kassel-Marcus (RRKM) modeling of leucine enkephalin dissociation, vibrational frequencies for the precursor ion were the same as reported elsewhere $[50,51]$. Transition-state vibrational frequencies were obtained by removing one $\mathrm{C}-\mathrm{N}$ stretch (reaction coordinate) from the set of precursor frequencies and scaling the frequencies in the range $500-1000 \mathrm{~cm}^{-1}$ by an appropriate constant to obtain the desired entropy factors [52].

\section{Results and Discussion}

\section{On- and Off-Resonance CAD of $\mathrm{Na}^{+}\left(\mathrm{H}_{2} \mathrm{O}\right)_{30}$ and $(Y G G F L+H)^{+}$}

The internal energy deposited into $\mathrm{Na}^{+}\left(\mathrm{H}_{2} \mathrm{O}\right)_{30}$ in onand off-resonance $\mathrm{CAD}$ was measured under a range of experimental conditions. This size cluster was chosen because it has a similar $\mathrm{m} / \mathrm{z}$ (563) and degrees-offreedom $(\mathrm{DOF}=267)$ as the protonated peptide leucine enkephalin $(m / z=556$; DOF $=228)$, so the collisional energy-transfer for these two ions should be similar. Collisional energy-transfer also depends on other factors, including collisional cross sections and on the vibrational frequencies of both the ion and target gas. In multiple collision experiments using the same target gas, where the time frame is sufficiently long that fragmentation is complete, i.e., all the energy-transfer that can occur does so before detection, effects of differences in the cross section and vibrational frequencies for these ions should be relatively small. In principle, a different cluster size could be used to take these effects into account if known.

Representative mass spectra for on-resonance CAD of $\mathrm{Na}^{+}\left(\mathrm{H}_{2} \mathrm{O}\right)_{30}$ and (YGGFL $\left.+\mathrm{H}\right)^{+}$measured with the same experimental conditions $\left(\mathrm{t}_{\mathrm{CAD}}=0.5 \mathrm{~s}\right.$ and maximum kinetic energies of 4.4-77 eV) are shown in Figure 1a and $b$, respectively. For $\mathrm{Na}^{+}\left(\mathrm{H}_{2} \mathrm{O}\right)_{30}$, the number of water molecules lost from the precursor ion increases with maximum collision energy from an average of $\sim 3.6$ to $\sim 20$ water molecules at 4.4 and $77 \mathrm{eV}$, respectively. At low kinetic energies, the distribution of product ions is relatively narrow (Figure 1a) but this distribution becomes broader with increasing collision energy. For $(\text { YGGFL }+\mathrm{H})^{+}$, there are no detectable fragments at $4.4 \mathrm{eV}$ but the major fragment ions, $\mathrm{b}_{5}^{+}, \mathrm{b}_{4}^{+}$, $\mathrm{a}_{4}^{+}$, and $\mathrm{a}_{4}^{+}-\mathrm{NH}_{3}$ appear and increase in abundance with increasing collision energy. At collision energies $>15$ $\mathrm{eV}$, additional product ions (F, Y, GF-28, $\mathrm{b}_{2}^{+}, \mathrm{y}_{2}^{+}, \mathrm{GGF}$, and the rearrangement product ions $[53,54] \mathrm{F}^{*} \mathrm{Y}-28$, $\left.F^{*} Y G, F^{*} Y G-28\right)$ are formed with lower abundance.

Representative SORI-CAD mass spectra of $\mathrm{Na}^{+}\left(\mathrm{H}_{2} \mathrm{O}\right)_{30}$ and $(\mathrm{YGGFL}+\mathrm{H})^{+}$as a function of irradiation time measured with the same experimental conditions $\left(\mathrm{V}_{p-p}=9\right.$ $\mathrm{V}, \Delta \omega=-1500 \mathrm{~Hz}$ ) are shown in Figure $2 \mathrm{a}$ and $\mathrm{b}$, respectively. For $\mathrm{Na}^{+}\left(\mathrm{H}_{2} \mathrm{O}\right)_{30}$, the distribution of product ions shifts only slightly to smaller hydrated metal ion clusters with increasing duration of the SORI rf irradiation time and the width of the product ion distribution becomes narrower. The number of water molecules lost from the precursor ion ranges from 2 to 9 and 6 to 11 with an average water molecule loss of $\sim 4.7$ and $\sim 7.9$ for irradiation times of 0.5 and $1.9 \mathrm{~s}$, respectively. Because precursor ions are more slowly activated in SORI-CAD than on-resonance CAD, the product ions have less excess internal energy. In addition, the product ions have cyclotron frequencies that are even more off-resonance from the excitation waveform and are not significantly activated further. This results in less sequential dissociation of the product ions than occurs with on-resonance CAD at higher collision energies. SORI-CAD of (YGGFL $+\mathrm{H})^{+}$results in formation of $b_{4}^{+}$and $b_{5}^{+}$that increase in intensity with increased rf pulse duration (Figure 2b).

\section{Internal Energy Deposition From Collisional Activation, $P_{C A}(E)$}

Hydrated sodium ion clusters dissociate by sequential loss of water molecules when activated. The internal energy deposition can be estimated from the relative abundances of the product ions in the dissociation mass spectrum of $\mathrm{Na}^{+}\left(\mathrm{H}_{2} \mathrm{O}\right)_{30}$ as a function of the energy necessary to form each product ion, which is the sum of 

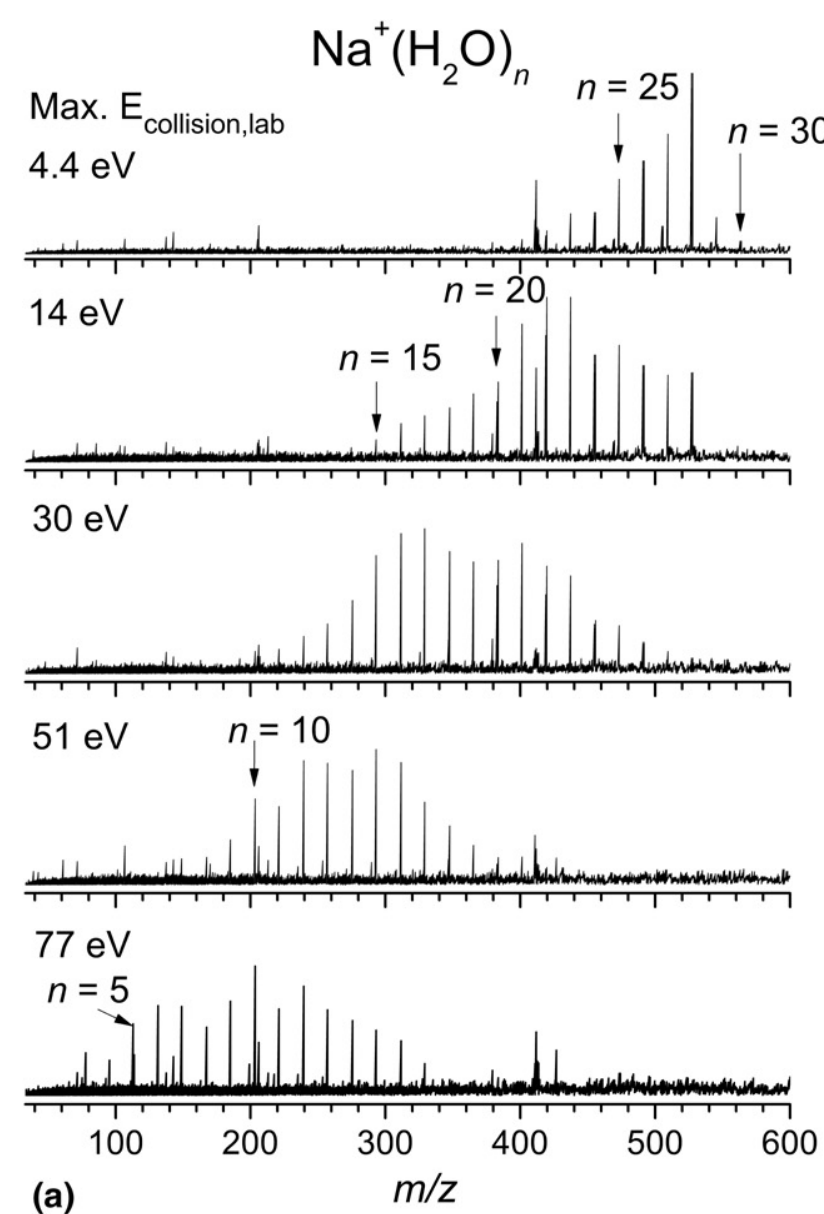
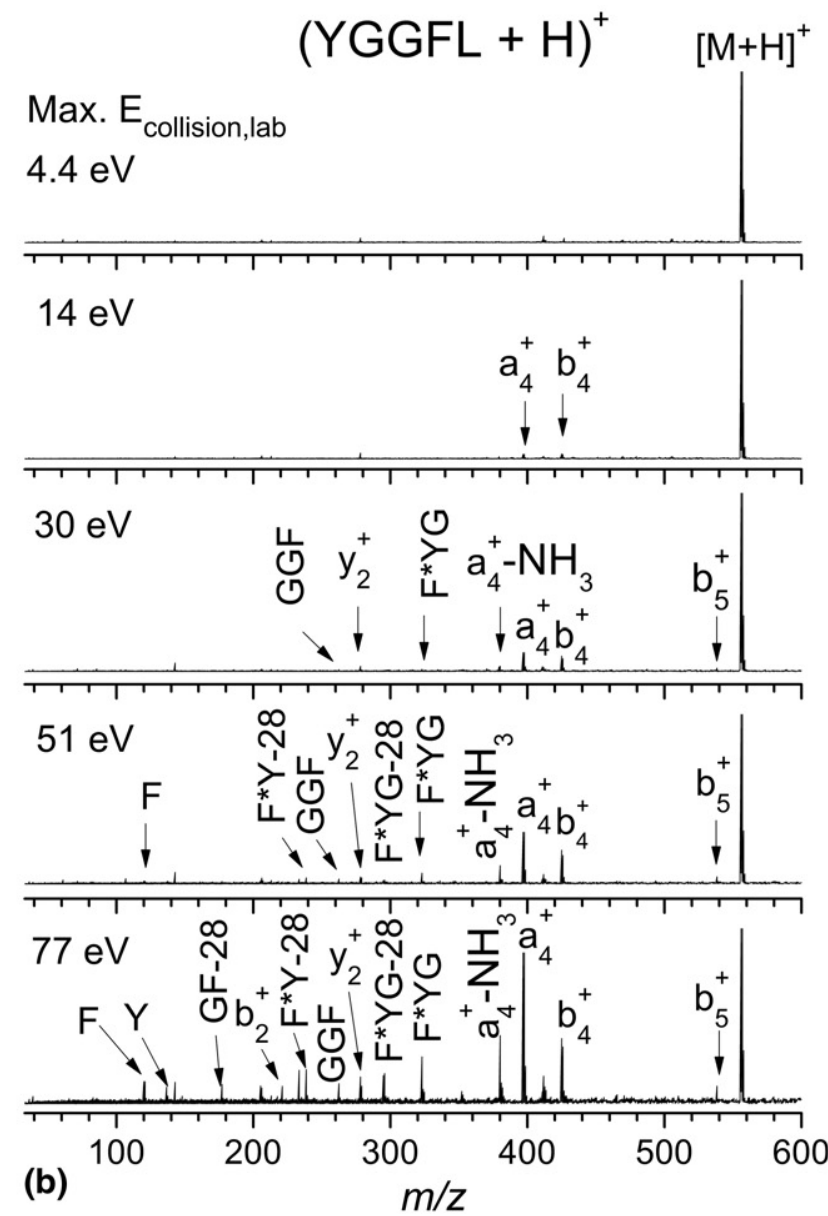

Figure 1. Representative on-resonance CAD mass spectra with increasing maximum lab frame collision energy at $\mathrm{t}_{\mathrm{CAD}}=0.5 \mathrm{~s}$ for $(\mathbf{a}) \mathrm{Na}^{+}\left(\mathrm{H}_{2} \mathrm{O}\right)_{30}(\mathrm{~m} / z 563)$ and $(\mathbf{b})(\mathrm{YGGFL}+\mathrm{H})^{+}(\mathrm{m} / z 556)$.

the sequential threshold dissociation energies and the energy that partitions into the products in the form of translational, rotational, and vibrational energy [44, 48]. Hydration enthalpies for small clusters of sodium have been measured [55], but values for the much larger clusters used here have not. These values are obtained from a discrete Thomson liquid drop model [56], and threshold dissociation energies are obtained from these values [44]. Because specific ion effects are not included, the model is less accurate at smaller cluster sizes, but the hydration enthalpy values obtained from the model rapidly approach the bulk vaporization of water at larger sizes. For example, measured binding enthalpies of $\mathrm{Na}^{+}\left(\mathrm{H}_{2} \mathrm{O}\right)_{n}, n=3$ to 6 are 15.8, 13.8, 12.3, and 10.7 $\mathrm{kcal} / \mathrm{mol}$, respectively [55], whereas the respective values obtained from the discrete Thomson liquid drop model are 14.9, 12.3, 11.1, and $10.4 \mathrm{kcal} / \mathrm{mol}$ [56]. For clusters with $n=7-30$, the calculated enthalpy values decrease from 9.8 to $9.2 \mathrm{kcal} / \mathrm{mol}$, close to the bulk vaporization value of water. A more thorough comparison of calculated and experimental water binding energies of mono and divalent ions is given elsewhere [56].

The energy that partitions into translational and rotational modes of the departing water molecules can be obtained from a statistical model if the temperature of the activated ion is known (under these conditions, the energy that is partitioned into the vibrational modes of the lost water molecules should be negligible). When a significant amount of energy is deposited into an ion on a time-scale shorter than dissociation, such as typically occurs when large hydrated ions capture an electron [48], the temperature of the activated ion can be high. Some of this deposited energy is partitioned into translational and rotational modes of the products and the rest of this energy goes into breaking the interactions between the water molecules and the cluster. For example, if $4 \mathrm{eV}$ is instantly deposited into $\mathrm{Na}^{+}\left(\mathrm{H}_{2} \mathrm{O}\right)_{30}$, initially at $133 \mathrm{~K}$, the energy lost to translation and rotations of the products accounts for $\sim 15 \%$ of the total energy deposited. When the energy is deposited more slowly through multiple collisions, water evaporation competes with energy deposition, so the temperature of the activated ions will remain significantly lower. Under these conditions, the energy lost to translation and rotations will be a significantly smaller fraction of the total energy deposited. In principle, the energy lost by these modes could be obtained if the collision and dissociation rates and the energy transferred in each 


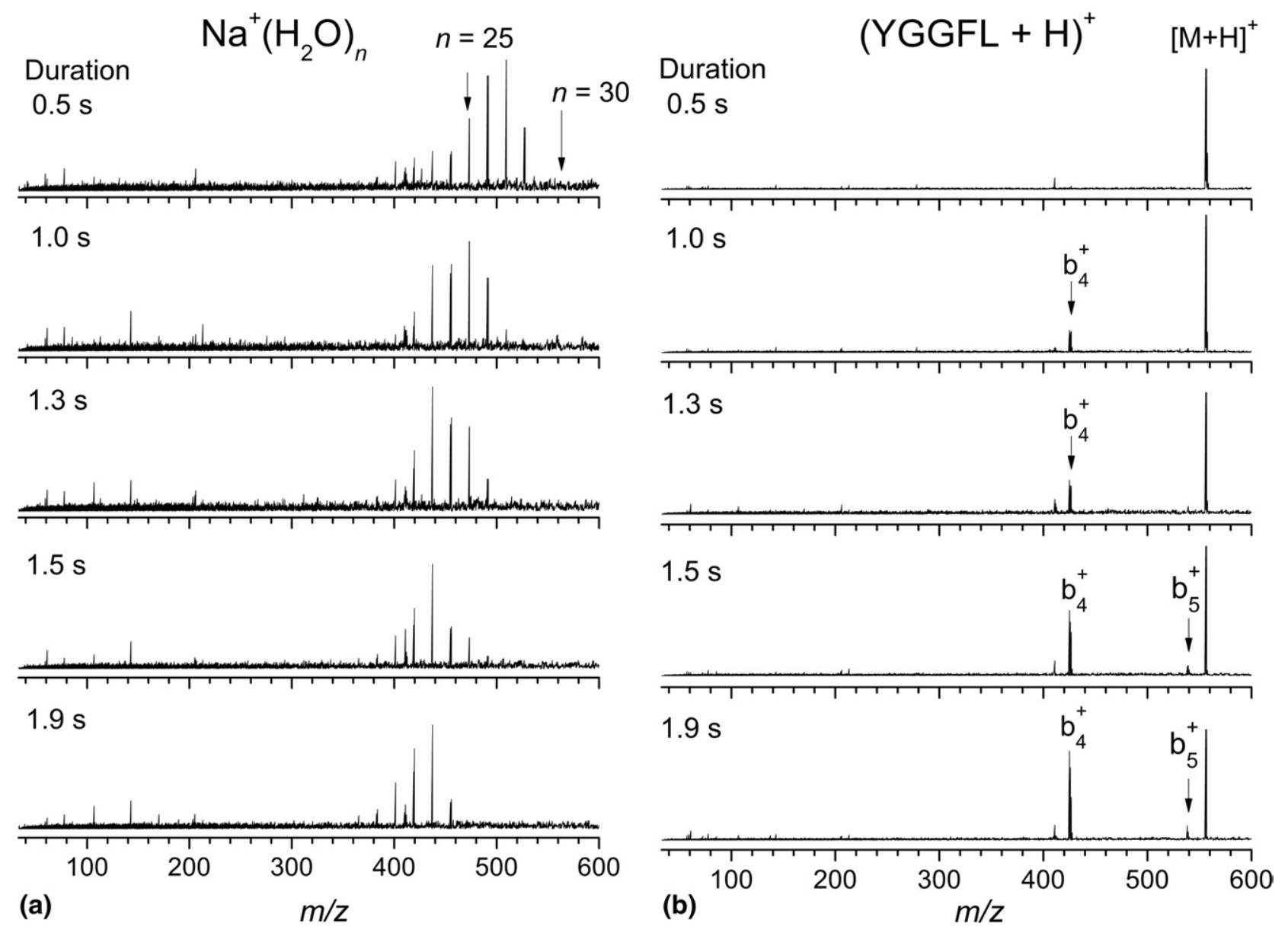

Figure 2. Representative SORI-CAD mass spectra with increasing duration of the applied offresonance pulse $\left(\mathrm{V}_{p-p}=9 \mathrm{~V}, \Delta \omega=-1500 \mathrm{~Hz}\right)$ for $(\mathbf{a}) \mathrm{Na}^{+}\left(\mathrm{H}_{2} \mathrm{O}\right)_{30}(m / z 563)$ and $(\mathbf{b})(\mathrm{YGGFL}+\mathrm{H})^{+}(\mathrm{m} / \mathrm{z}$ 556).

collision were known. For simplicity, only the sum of the threshold dissociation energies are used to estimate the energy required to evaporate sequential water molecules from the hydrated ion cluster.

To determine the internal energy deposited, $\mathrm{P}_{\mathrm{CA}}(\mathrm{E})$, due to collisions alone, the data are corrected for dissociation of the hydrated ion cluster by BIRD that occurs over the duration of the collisional activation event. All $\mathrm{P}_{\mathrm{CA}}(\mathrm{E})$ curves and average energies that are reported are corrected for BIRD. To obtain a continuous energy deposition function from the experimentally measured $\mathrm{P}_{\mathrm{CA}}(\mathrm{E})$ curves that have a discrete number of values, the experimental data were fit with the analytical expression (eq 1):

$$
\mathrm{P}_{\mathrm{CA}}(\mathrm{E}, a, b)=\frac{\mathrm{E}^{a-1} \cdot \exp (-\mathrm{E} / b)}{\Gamma(a) \cdot b^{a}}
$$

where $\mathrm{E}$ is the internal energy and $a$ and $b$ are constants determined by minimization between the experimental data and the analytical expression using an optimized Levenberg-Marquardt algorithm. Laskin et al. use an analogous analytical expression that has more fitting parameters, to obtain semi-empirical energy distribution curves in CAD and SID experiments [30-33]. This analytical function fits all the experimentally measured $P_{C A}(E)$ curves very well.

Representative plots of the internal energy deposited into $\mathrm{Na}^{+}\left(\mathrm{H}_{2} \mathrm{O}\right)_{30}$ by on- and off-resonance CAD are shown in Figure $3 a$ and $b$, respectively. With onresonance $\mathrm{CAD}$, the internal energy deposition increases to higher average energies and becomes broader with increasing lab frame collision energy (Figure 3a). With SORI-CAD, the internal energy deposition increases to slightly higher average energies as the duration of the rf pulse is increased, but the average internal energy deposition remains constant at $\sim 1.7 \mathrm{eV}$ after a pulse duration of about $1.5 \mathrm{~s}$.

Relating $P_{C A}(E)$ for $\mathrm{Na}^{+}\left(\mathrm{H}_{2} \mathrm{O}\right)_{30}$ and $(Y G G F L+H)^{+}$

In SORI-CAD, the precursor ion is slowly "heated" until there is sufficient energy and time to break a bond, resulting in product ions that do not have much excess energy and are not further activated significantly. Be- 


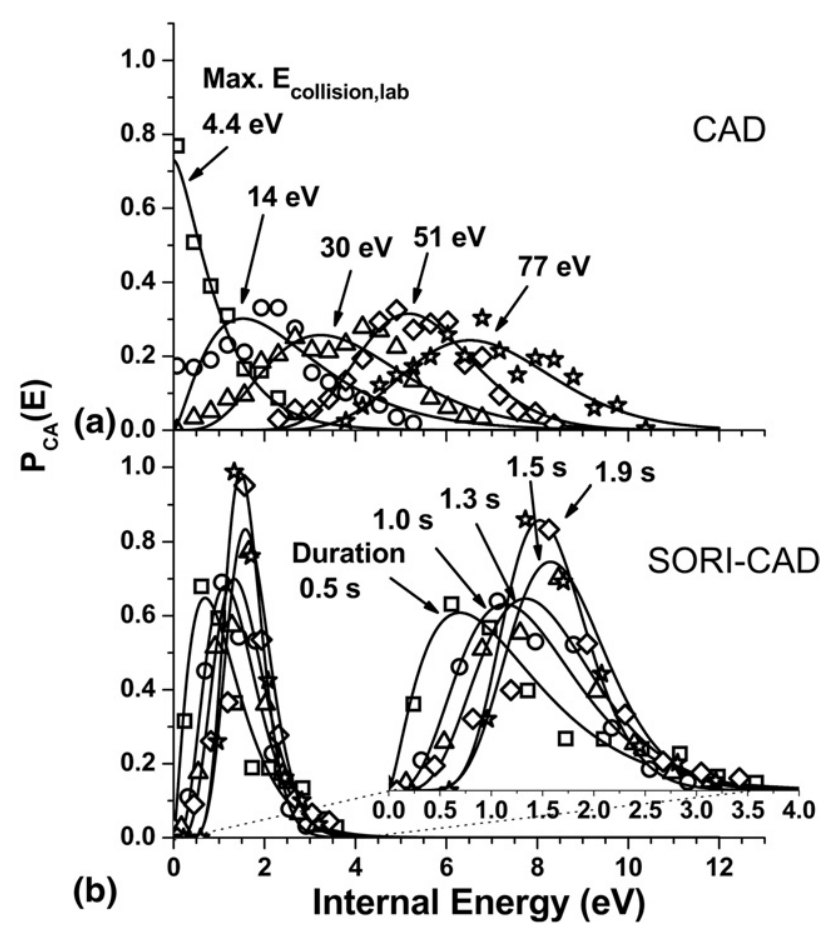

Figure 3. Calculated internal energy deposition curves using the product ion mass spectra of the activated precursor, $\mathrm{Na}^{+}\left(\mathrm{H}_{2} \mathrm{O}\right)_{30}$, shown in Figures (1a) and (2a), respectively, for (a) on-resonance CAD with increasing maximum lab frame collision energy at $\mathrm{t}_{\mathrm{CAD}}=0.5 \mathrm{~s}$ and (b) SORI-CAD with increasing duration of the SORI rf pulse (insert: expansion of the energy scale from 0 to $4 \mathrm{eV}$ ).

cause the dissociation threshold for loss of a water molecule from $\mathrm{Na}^{+}\left(\mathrm{H}_{2} \mathrm{O}\right)_{30}(\sim 0.37 \mathrm{eV})$ is much lower than the dissociation threshold for leucine enkephalin $(\sim 1.1 \mathrm{eV})$ [57], less internal energy is required to dissociate $\mathrm{Na}^{+}\left(\mathrm{H}_{2} \mathrm{O}\right)_{30}$ than leucine enkephalin. Thus, more energy will be deposited into leucine enkephalin than $\mathrm{Na}^{+}\left(\mathrm{H}_{2} \mathrm{O}\right)_{30}$ in these SORI-CAD experiments, i.e., the measured internal energy deposition for $\mathrm{Na}^{+}\left(\mathrm{H}_{2} \mathrm{O}\right)_{30}$ is lower than that for leucine enkephalin. In contrast, because excitation for on-resonance CAD is rapid (200 $\mu \mathrm{s})$ compared with the collision frequency, the internal energy deposition obtained from the dissociation products of $\mathrm{Na}^{+}\left(\mathrm{H}_{2} \mathrm{O}\right)_{30}$ should be very close to that for leucine enkephalin. Thus, the internal energy deposition for $\mathrm{Na}^{+}\left(\mathrm{H}_{2} \mathrm{O}\right)_{30}$ and (YGGFL $\left.+\mathrm{H}\right)^{+}$in on-resonance CAD was studied in more detail.

\section{Total Peptide Ion Internal Energy Distribution, $P_{\text {total }}(E)$}

The product ion distribution from $\mathrm{Na}^{+}\left(\mathrm{H}_{2} \mathrm{O}\right)_{30}$ reflects the energy added to the precursor ion in these experiments. To obtain information about the dissociation energies and entropies from modeling of the dissociation processes, the total internal energy of the peptide ion must be known. The total internal energy can be obtained by convolving the initial thermal internal energy distribution, $\mathrm{P}_{\text {thermal }}(\mathrm{E})$, and the internal energy deposited upon activation, $\mathrm{P}_{\mathrm{CA}}(\mathrm{E})$. The initial internal energy is given by a Boltzmann distribution at $133 \mathrm{~K}$ (Figure 4, top) which corresponds to an average energy of $\sim 0.25 \mathrm{eV}$. The internal energy deposited due to collisions in on-resonance $\mathrm{CAD}$ as a function of reaction time, $\mathrm{t}_{\mathrm{CAD}}$, at collision energies of $4.4 \mathrm{eV}$ and $77 \mathrm{eV}$, is shown in Figure $4 a$ and $b$, respectively. The internal energy deposition increases and the distribution becomes broader with increasing $\mathrm{t}_{\mathrm{CAD}}$, but no significant change occurs for $t_{C A D} \geq 0.15 \mathrm{~s}$. By comparison, the Boltzmann internal energy distribution of (YGGFL + $\mathrm{H})^{+}$at $133 \mathrm{~K}$ is much narrower than the internal energy deposition due to collisional activation (Figure 4). Thus, the total internal energy of the peptide ion is estimated by adding $0.25 \mathrm{eV}$ to the measured collisional energy deposition to account for the initial internal energy of the precursor ion.

\section{Collisional Energy Transfer Efficiency}

The absence of additional dissociation for $t_{C A D}>0.15 \mathrm{~s}$ indicates that the kinetic energy of the precursor ion is reduced to a value where no further collisional activation occurs. Thus, the efficiency of collision energy transferred in these experiments can be obtained from $\mathrm{P}_{\mathrm{CA}}(\mathrm{E})$ as a function of maximum lab frame kinetic energy at larger $t_{C A D}$. Data for the average number of water molecules lost, the corresponding average energy deposited, and the collision energy-transfer efficiency for on-resonance $\mathrm{CAD}\left(\mathrm{t}_{\mathrm{CAD}}=0.5 \mathrm{~s}\right)$ are shown in Figure 5. The average internal energy deposited increases with maximum lab frame kinetic energy (Figure $5 b)$, but these data indicate that the internal energy deposition becomes less efficient as the collision energy is increased. Cooks and coworkers observed a similar trend in multiple-collision CAD in a quadrupole mass spectrometer using metal ion carbonyls as thermometer ions [37]. This trend is also consistent with the observation of Harrison and coworkers who used the ratio of the product ions, $\mathrm{C}_{7} \mathrm{H}_{7}^{+\cdot}$ and $\mathrm{C}_{7} \mathrm{H}_{8}^{++}$, formed by dissociation of $n$-alkylbenzene molecular ions as a gauge of the internal energy transferred in low-energy (2-100 eV) collisions [58]. The ratio of these product ions plateaus at higher collision energies, consistent with less efficient energy-transfer at higher collision energies.

The collisional energy-transfer efficiency in onresonance $C A D$ as a function of maximum lab frame kinetic energy is obtained from eq 2 :

$$
\text { Conversion Efficiency }(\%)=\frac{\text { Avg. } E_{\text {deposited }}}{\text { Max. } E_{\text {collision,lab }}} \cdot 100 \%
$$

The conversion efficiency decreases with increased collision energy from $16 \%$ at $4.4 \mathrm{eV}$ to around $9 \%$ at $77 \mathrm{eV}$. Similar conversion efficiencies have been reported by $\mathrm{Wu}$ et al. for alkali chloride cluster ions in single collisions with Ar gas (6\%-14\% for a lab frame kine- 

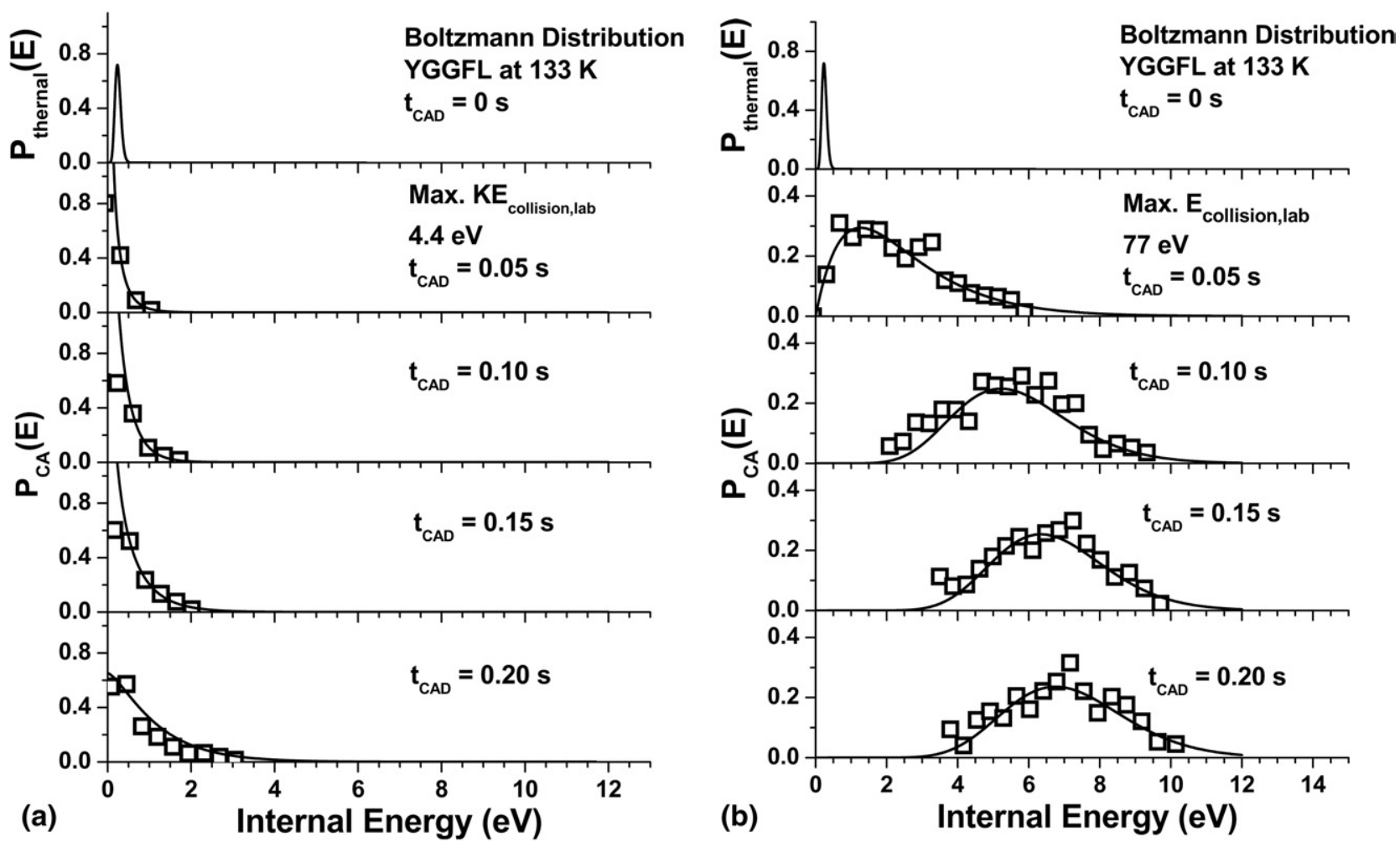

Figure 4. Thermal Boltzmann energy distribution, $\mathrm{P}_{\text {thermal }}(\mathrm{E})$, of $(\mathrm{YGGFL}+\mathrm{H})^{+}$at $133 \mathrm{~K}$ (top). Representative internal energy deposition, $\mathrm{P}_{\mathrm{CA}}(\mathrm{E})$, curves due to collisional activation in on-resonance $\mathrm{CAD}$ as a function of reaction time ( $\left.\mathrm{t}_{\mathrm{CAD}}\right)$ at maximum lab frame collision energy (a) $4.4 \mathrm{eV}$ and (b) $77 \mathrm{eV}$.

tic energy of $20 \mathrm{eV}, 4.9 \%-11 \%$ for a lab frame kinetic energy of $30 \mathrm{eV}$, and $3.8 \%-8 \%$ for a lab frame kinetic energy of $50 \mathrm{eV}$ ) [59]. This trend is consistent with energy-transfer in low collision energy (1-100 eV) CAD occurring via a combination of two limiting mechanisms [24, 60,61]. At very low kinetic energies and for polarizable neutral targets, complex formation is favored in which the interaction time between the precursor ion and the neutral target is long (surviving for many vibrational periods) resulting in efficient energytransfer [24]. At high collision energies and for less polarizable neutral targets, energy-transfer occurring through a direct mechanism via impulsive collisions is favored; the collisions are mainly elastic, and less energytransfer occurs [24].

\section{Dissociation of Leucine Enkephalin}

The normalized abundances of (YGGFL $+\mathrm{H})^{+}$, the major fragments $\left(\mathrm{b}_{5}^{+}, \mathrm{b}_{4}^{+}, \mathrm{a}_{4}^{+}\right.$, and $\left.\mathrm{a}_{-}^{+}-\mathrm{NH}_{3}\right)$, and the sum of the minor fragments (F, Y, GF-28, $\mathrm{b}_{2}^{+}, \mathrm{y}_{2}^{+}, \mathrm{GGF}$, and rearrangement product ions $F^{*} Y-28, F^{*} Y G, F^{*} Y G-28$ ) formed by on-resonance $\mathrm{CAD}$ as a function of collision energy are shown in Figure 6. The product ions, $\mathrm{b}_{4}^{+}$and $\mathrm{a}_{4}^{+}$, are formed first with similar abundances at collision energies of $\sim 7.5 \mathrm{eV}$ corresponding to an average precursor ion internal energy of $\sim 1.4 \mathrm{eV}$. At higher collision/internal energies, the $\mathrm{a}_{4}^{+}$abundance is greater than that of $b_{4}^{+}$. The $b_{5}^{+}$and a few lower abundance product ions appear at collision energies slightly above $20 \mathrm{eV}$, corresponding to an average internal energy of $\sim 2.9 \mathrm{eV}$. Previous BIRD [57] and SORI-CAD [62] double resonance experiments show that $(\mathrm{YGGFL}+\mathrm{H})^{+}$dissociates to form $b_{5}^{+}$and $b_{4}^{+}$, and all other product ions are formed by sequential dissociation of $b_{4}^{+}$, a result consistent with a thermal activation experiment in an ion trap mass spectrometer [54]. However, some evidence for a small abundance of $\mathrm{a}_{4}^{+}$formed directly from $(\text { YGGFL }+\mathrm{H})^{+}$has been reported [63].

Additional competing higher energy dissociation pathways of protonated leucine enkephalin can potentially be accessed if the internal energy is sufficiently high [30]. However, the lower energy dissociation channels are expected to be significantly favored under the multiple collision conditions and relatively low centerof-mass collision energies in these experiments. The branching ratio of the $b_{4}^{+}$and $b_{5}^{+}$dissociation pathways with $\mathrm{E}_{\text {collision,lab }}$ values up to $\sim 35 \mathrm{eV}$ are within the range of values reported in previous experiments [62] in which only these two products are known to form directly from the precursor ion. This is consistent with the $b_{4}^{+}$and $b_{5}^{+}$dissociation channels being the only significant accessible pathways under the conditions of these experiments. 


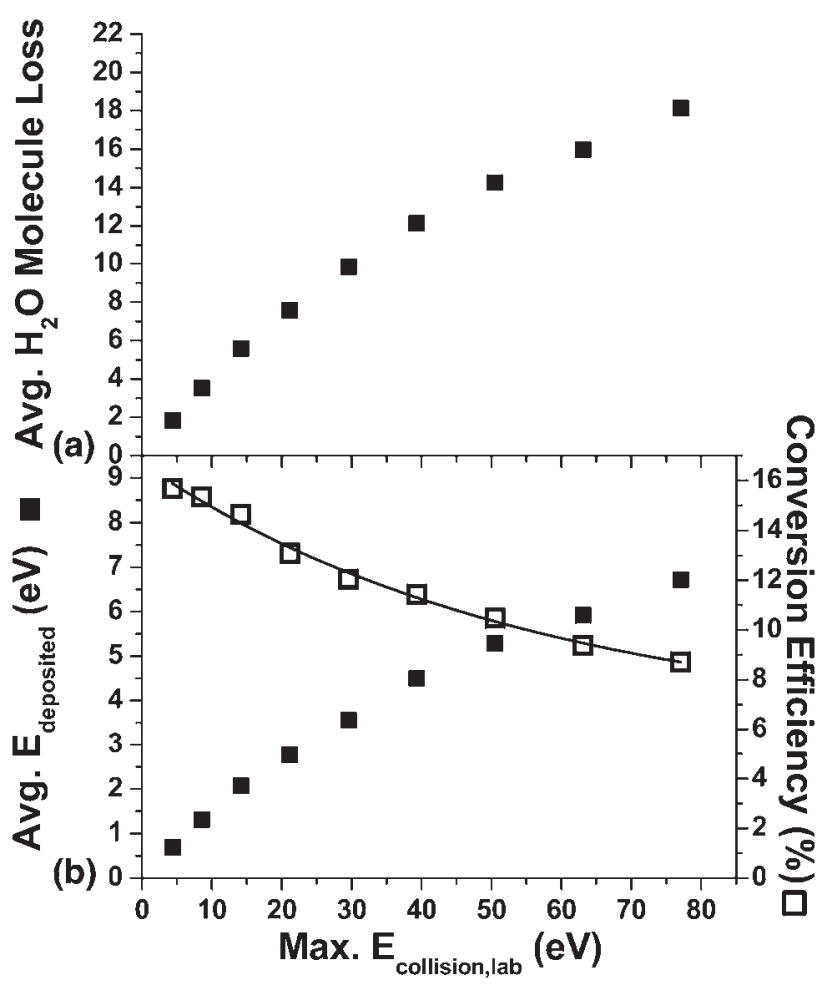

Figure 5. (a) Average number of water molecules lost by $\mathrm{Na}^{+}\left(\mathrm{H}_{2} \mathrm{O}\right)_{30}$ in on-resonance CAD as a function of maximum lab frame collision energy. (b) Average internal energy (filled square) deposited obtained from the average water molecule loss from (a) and the corresponding conversion efficiency (open square) of the maximum lab frame collision energy into average internal energy in on-resonance $\mathrm{CAD}$ as a function of maximum lab frame collision energy.

\section{RRKM Calculations and Modeling the Fragmentation of Leucine Enkephalin}

Only the two direct dissociation pathways of (YGGFL + $\mathrm{H})^{+}$to form $\mathrm{b}_{5}^{+}$and $\mathrm{b}_{4}^{+}$are modeled. The abundances of the other product ions are added to the abundance of $b_{4}^{+}$ [62]. Microcanonical rate constants as a function of internal energy for the $b_{5}^{+}$and $b_{4}^{+}$reaction channels of $(\text { YGGFL }+\mathrm{H})^{+}$are calculated using the RRKM/QET expression:

$$
k(E)=\frac{\sigma \cdot N^{T S}\left(E-E_{0}\right)}{h \cdot \rho(E)}
$$

where $\sigma$ is the reaction degeneracy, $\mathrm{N}^{\mathrm{TS}}\left(\mathrm{E}-\mathrm{E}_{0}\right)$ is the transition-state sum of states from 0 to $\left(\mathrm{E}-\mathrm{E}_{0}\right)$ obtained with the direct count method [52], $h$ is Planck's constant, and $\rho(\mathrm{E})$ is the density of states of the precursor ion at energy $\mathrm{E}$ also obtained with the direct count method [52]. Breakdown curves for the formation of $b_{5}^{+}$ and $\mathrm{b}_{4}^{+}$and for the dissociation of (YGGFL $\left.+\mathrm{H}\right)^{+}$are constructed as a function of internal energy using reaction time, $\mathrm{t}_{\mathrm{CAD}}$, with the following equations:

$$
[\text { Precursor }]\left(E, t_{C A D}\right)=\exp \left[-\sum_{i} k_{i}(E) \cdot t_{C A D}\right]
$$

[Product, $i]\left(E, t_{C A D}\right)$

$$
=\frac{k_{i}(E)}{\sum_{i} k_{i}(E)} \cdot\left[1-\exp \left(-\sum_{i} k_{i}(E) \cdot t_{C A D}\right)\right]
$$

where [Precursor] $\left(\mathrm{E}, \mathrm{t}_{\mathrm{CAD}}\right)$, [Product, $\left.i\right]\left(\mathrm{E}, \mathrm{t}_{\mathrm{CAD}}\right)$ are the energy and reaction time-dependent abundances of the precursor ion and product ion $i$, respectively, and $k_{i}(E)$ is the microcanonical rate constant for formation of product ion $i$ as a function of internal energy. The normalized abundances for the precursor ion and the product ions are modeled at each collision energy, $\mathrm{E}_{\mathrm{coll}, \mathrm{lab}}$, and reaction time, $\mathrm{t}_{\mathrm{CAD}}$, by convolving the total internal energy distributions and corresponding breakdown curves:

$$
\begin{aligned}
& I_{\text {precursor }}\left(E_{\text {coll, lab }}, t_{C A D}\right)
\end{aligned}
$$

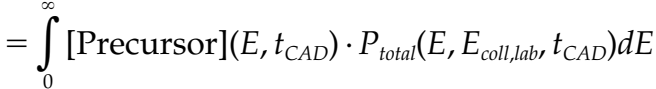

$$
\begin{aligned}
& I_{\text {product }, i}\left(E_{\text {coll, lab }}, t_{C A D}\right) \\
& =\int_{0}^{\infty}[\text { Product, } i]\left(E, t_{C A D}\right) \cdot P_{\text {total }}\left(E, E_{\text {coll l, lab }}, t_{C A D}\right) d E
\end{aligned}
$$

where $P_{\text {total }}\left(E, E_{\text {coll,lab }}, t_{C A D}\right)$ is the total internal energy distribution of the peptide ion at a specific collision energy and reaction time. In on-resonance collisional activation, the internal energy deposited changes as a function of reaction time with no significant change in energy deposition occurring beyond $0.15 \mathrm{~s}$ for all collision energies studied (data shown for 4.4 and $77 \mathrm{eV}$ in Figure 4). Thus, to calculate the final normalized abundances for $(\mathrm{YGGFL}+\mathrm{H})^{+}$and $\mathrm{b}_{5}^{+}$and $\mathrm{b}_{4}^{+}$, the change in

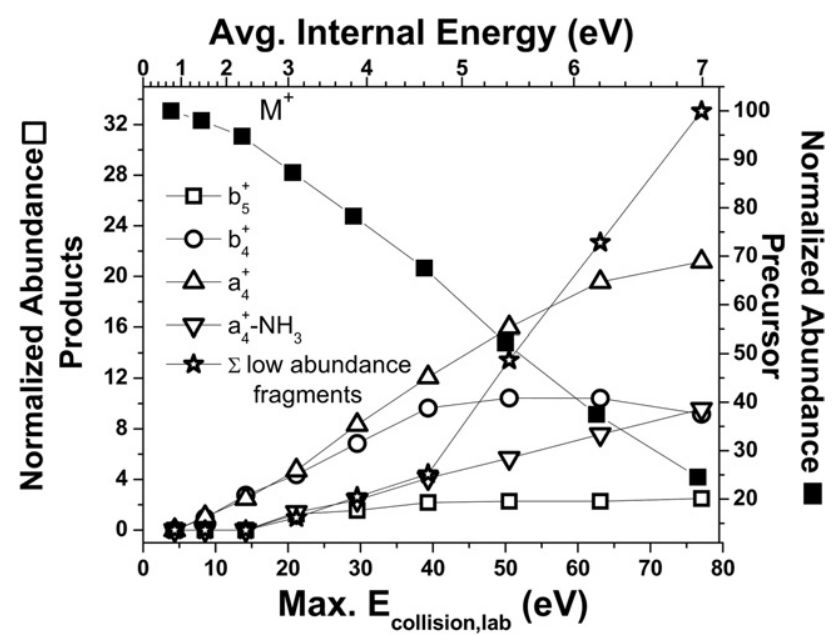

Figure 6. Normalized abundances for (YGGFL $+\mathrm{H})^{+}$(filled square), the product ions $\mathrm{b}_{5}^{+}, \mathrm{b}_{4}^{+}, \mathrm{a}_{4}^{+}$, and $\mathrm{a}_{4}^{+}-\mathrm{NH}_{3}$, and the sum of all other low abundance product ions (F, Y, GF-28, $\mathrm{b}_{2}^{+}, \mathrm{y}_{2}^{+}, \mathrm{GGF}$, and rearrangement product ions $\left.F^{*} Y-28, F^{*} Y G, F^{*} Y G-28\right)$ (open symbols) as a function of maximum lab frame collision energy and average internal energy in on-resonance CAD. 
intensities of these ions is evaluated with a crude $0.05 \mathrm{~s}$ time integration step, up to $0.15 \mathrm{~s}$. The following approximations about the internal energy distribution of the activated $(\mathrm{YGGFL}+\mathrm{H})^{+}$are made: At time $0.0 \mathrm{~s}$, the internal energy distribution of $(\mathrm{YGGFL}+\mathrm{H})^{+}$is approximated by $\mathrm{P}_{\text {thermal }}(\mathrm{E})$ at $133 \mathrm{~K}$. At $\mathrm{t}=0.05 \mathrm{~s}$ the internal energy distribution of the peptide is approximated using $\mathrm{P}_{\text {total }}\left(\mathrm{E}, \mathrm{E}_{\mathrm{coll}, \mathrm{lab}}, \mathrm{t}_{\mathrm{CAD}}=0.05 \mathrm{~s}\right)$; and at $\mathrm{t}=$ $0.10 \mathrm{~s}$ the energy distribution is approximated using $P_{\text {total }}\left(E, E_{\text {coll,lab, }} t_{C A D}=0.10 \mathrm{~s}\right)$. Final precursor and product ion abundances are then calculated using the following equations:

$$
\begin{aligned}
& I_{\text {precursor }}^{\text {final }}\left(E_{\text {coll, lab }}\right) \\
& \quad=I_{\text {precursor }}\left(E_{\text {coll,lab }}, 0.05 s\right) \cdot I_{\text {precursor }}\left(E_{\text {coll, lab },} 0.10 s\right) \\
& I_{\text {product }, i}^{\text {final }}\left(E_{\text {coll, lab }}\right)=I_{\text {product }, i}\left(E_{\text {coll,lab, }} 0.05 s\right) \\
& \quad+I_{\text {product }, i}\left(E_{\text {coll,lab, }}, 0.10 s\right) \cdot I_{\text {precursor }}\left(E_{\text {coll, lab }}, 0.05 s\right)
\end{aligned}
$$

This procedure is repeated to calculate final normalized abundances at all collision energies studied. The accuracy of these calculations will improve by using a smaller time-step to better approximate the evolution of the internal energy distribution of the peptide ion with time.

\section{Fitting the Experimental Fragmentation Data}

Because formation of $\mathrm{b}_{5}{ }^{+}$is a very minor process (Figure 6), it was excluded as a separate process in the initial modeling, i.e., the overall dissociation of leucine enkephalin was modeled by searching for $E_{0}$ and $\log (A)$ values for the total microcanonical dissociation rate constant, $\mathrm{k}_{\text {total }}(\mathrm{E})=\mathrm{k}_{\mathrm{b} 5}(\mathrm{E})+\mathrm{k}_{\mathrm{b} 4}(\mathrm{E})$, that best fit the experimental data. $\mathrm{E}_{0}$ was varied from 0.4 to $2.58 \mathrm{eV}$ in $0.02 \mathrm{eV}$ increments, and $\log (\mathrm{A})$ was varied from 3.1 to 19.2 in $\sim 0.3$ increments. A maximum $\log (\mathrm{A})$ value of 19.2 was used because reliable higher $\log (\mathrm{A})$ values for the dissociation of protonated peptides have not been reported [19]. The sum of the squared deviation between the modeled and the experimental data for the depletion of $(\text { YGGFL }+\mathrm{H})^{+}$as a function of threshold dissociation energy and entropy factor was calculated and is shown in Figure 7. The best fit to the experimental data is indicated by the smallest sum of squared error, shown by the black curved line. The threshold dissociation energy and entropy factor are correlated, and numerous combinations of these values result in a good fit to the experimental data with $\mathrm{E}_{0}$ values ranging from $1.12 \mathrm{eV}$ at $\log (\mathrm{A})=3.1$ to $1.75 \mathrm{eV}$ at $\log (\mathrm{A})=19.2$. Activation energies and pre-exponential factors reported from BIRD, thermal dissociation in a heated capillary flow reactor attached to the entrance capillary of a mass spectrometer, and thermal dissociation in an ion trap are $1.09 \pm 0.06 \mathrm{eV}$ and $\log (\mathrm{A})=10.5 \pm 0.6$ [57], $1.66 \mathrm{eV}$ and $\log (\mathrm{A})=15.7$ [64], and $1.28 \pm 0.08 \mathrm{eV}$ and

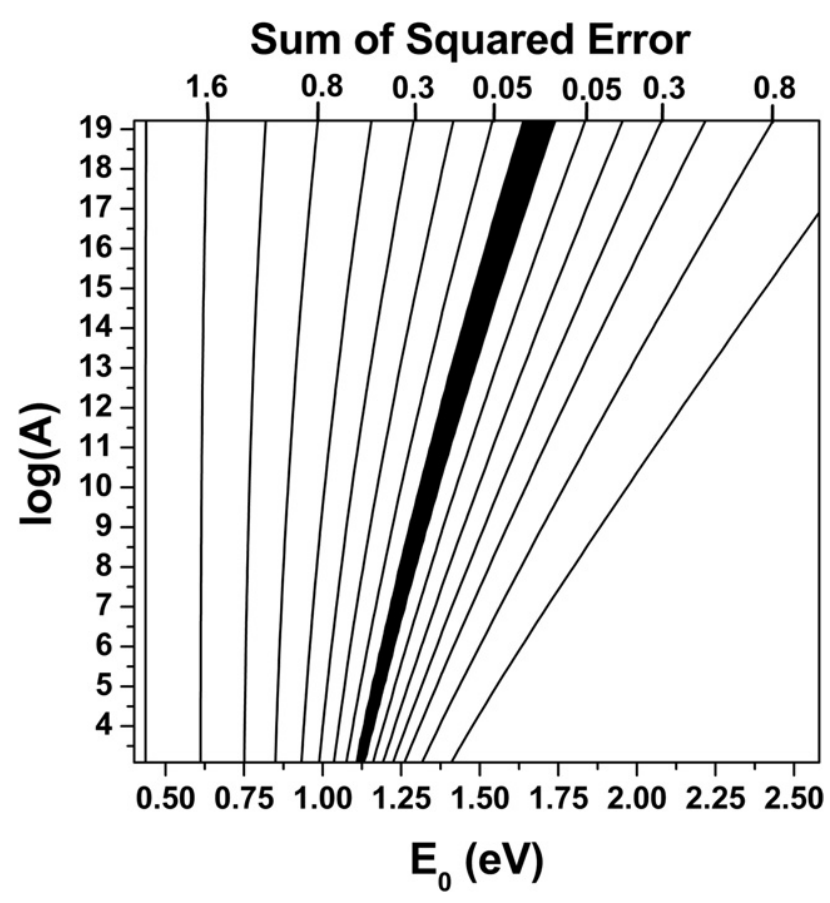

Figure 7. Parameter space for fitting the experimental dissociation data for $(\text { YGGFL }+\mathrm{H})^{+}$. The sum of the squared error for the calculated and experimental data is plotted as a function of threshold dissociation energy and entropy factor. The darkest line corresponds to a sum of squared error $\leq 0.01$ and represents the best fit to the experimental data.

$\log (\mathrm{A})=12.6 \pm 0.9[65]$, respectively. The values from the fit of the CAD data fall within the range (1.09-1.66 $\mathrm{eV})[57,64,65]$ of the previously reported activation energies for the overall dissociation of leucine enkephalin.

A more detailed approach to the modeling takes into account formation of both $b_{5}^{+}$and $b_{4}^{+}$. Thermochemical values have also been measured previously for these two pathways from BIRD [57] and SID [30] experiments. The ratio of the $b_{4}^{+}$to $b_{5}^{+}$dissociation pathways increases with increasing collision energy (Figure 8a) indicating that formation of $\mathrm{b}_{4}^{+}$is entropically favored, consistent with BIRD [57] and SID [30] experiments. The threshold dissociation energies and entropy factors for the individual $b_{4}^{+}$and $b_{5}^{+}$reaction channels were varied in an extensive search similar to the one for the overall dissociation of the precursor ion. However, there were numerous combinations of threshold energies and entropy factors that fit the experimental data. For instance, one set of thermochemical values that resulted in good fits were the following: $\mathrm{E}_{0}=1.30 \mathrm{eV}$ and $\log (\mathrm{A})=9.6$ for $\mathrm{b}_{4}^{+}$, and $\mathrm{E}_{0}=1.37 \mathrm{eV}$ and $\log (\mathrm{A})=$ 7.5 for $b_{5}^{+}$(Figure $8 b$ ). These threshold energies and entropy factors are consistent with values measured from BIRD [57] experiments $\left(b_{4}^{+}: E_{a}=1.11 \pm 0.06 \mathrm{eV}\right.$ and $\log (\mathrm{A})=10.7 \pm 0.6, \mathrm{~b}_{5}^{+}: \mathrm{E}_{\mathrm{a}}=0.99 \pm 0.07$ and $\log (\mathrm{A})=$ $8.7 \pm 0.8)$ and those obtained from SID [30] experiments $\left(\mathrm{b}_{4}^{+}: \mathrm{E}_{0}=1.14 \mathrm{eV}\right.$ and $\log (\mathrm{A})=10.18, \mathrm{~b}_{5}^{+}: \mathrm{E}_{0}=1.20 \mathrm{eV}$ and $\log (\mathrm{A})=9.04)$. 


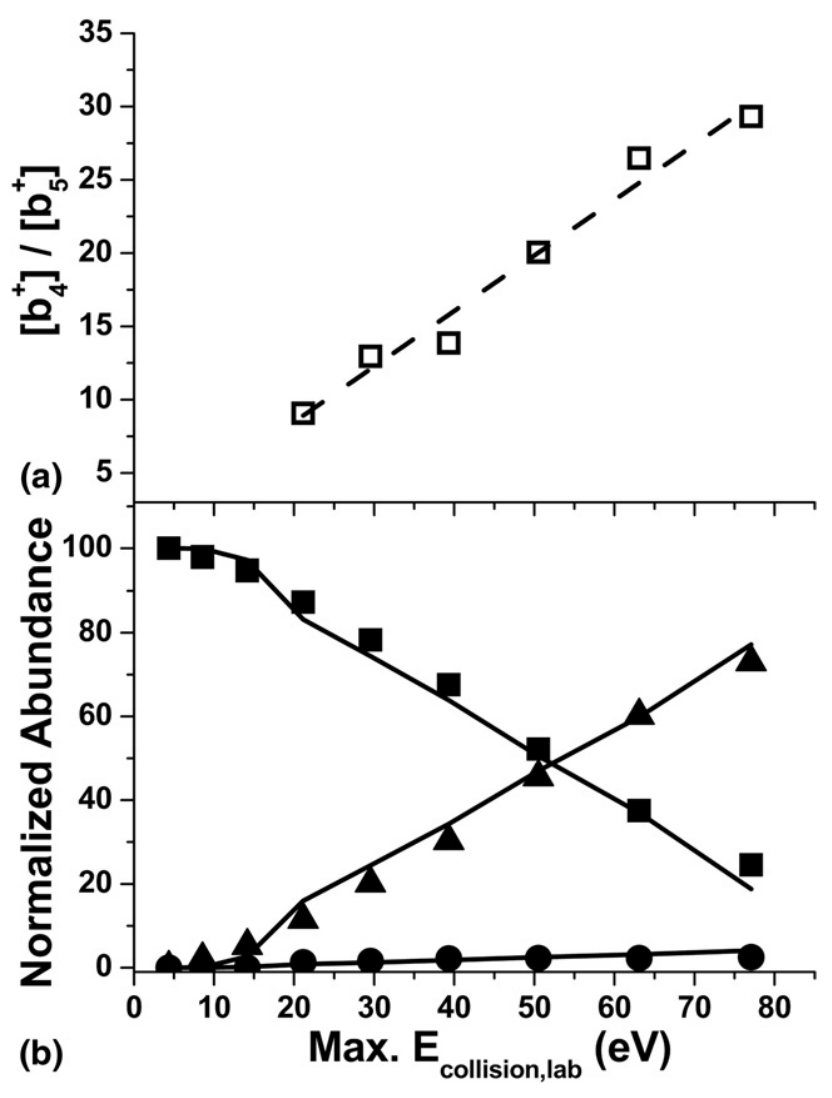

Figure 8. (a) Abundance ratio of the $b_{4}^{+}$and $b_{5}^{+}$product ions of $(\text { YGGFL }+\mathrm{H})^{+}$as a function of lab frame collision energy. (b) Measured normalized abundances and calculated fits (lines) as a function of lab frame collision energy for the dissociation of $(\text { YGGFL }+\mathrm{H})^{+}$(filled square), the formation of $b_{4}^{+}$(filled triangle) with $\mathrm{E}_{0}=1.30 \mathrm{eV}$ and $\log (\mathrm{A})=9.6$, and $\mathrm{b}_{5}^{+}$(filled circle) with $\mathrm{E}_{0}=$ $1.37 \mathrm{eV}$ and $\log (\mathrm{A})=7.5$.

\section{Conclusions}

The internal energy distribution in on-resonance CAD and SORI-CAD can be measured using ion nanocalorimetry. Both the average internal energy deposited and the shape of the distributions are measured for hydrated ions as a function of collision energy and/or reaction time. The energy deposited into a peptide ion of comparable size in on-resonance CAD can be inferred from the hydrated ion data. By modeling the abundances of ions as a function of the measured internal energy deposition, information about the fragmentation energies and entropies of a peptide can be obtained. However, the threshold dissociation energy and entropy values are correlated for data measured at a single time point, which results in a relatively broad range of threshold dissociation energies that can fit the experimental data. More accurate values could be obtained from time resolved fragmentation data, which would provide additional constraints on the modeling. Although not as accurate as BIRD, this method has the advantage that data can be rapidly obtained. Because the internal energy deposition in CAD is obtained experimentally, the number of parameters required to model peptide dissociation data is reduced. Thus, this nanocalorimetry method could be used to increase the accuracy of other methods [30-33] where modeling of CAD or SID data is done to obtain information about dissociation energies and entropies.

\section{Acknowledgments}

The authors thank Dr. Philip M. Remeš for providing vibrational frequencies for protonated leucine enkephalin, William A. Donald for helpful discussions, and the National Science Foundation (CHE-0718790) for generous financial support.

\section{References}

1. Wysocki, V. H.; Joyce, K. E.; Jones, C. M.; Beardsley, R. L. SurfaceInduced Dissociation of Small Molecules, Peptides, and Non-Covalent Protein Complexes. J. Am. Soc. Mass Spectrom. 2008, 19, 190-208.

2. Mabud, M. A.; Dekrey, M. J.; Cooks, R. G. Surface-Induced Dissociation of Molecular Ions. Int. J. Mass Spectrom. Ion Processes 1985, 67, 285-294.

3. Laskin, J.; Futrell, J. H. Surface-Induced Dissociation of Peptide Ions: Kinetics and Dynamics. J. Am. Soc. Mass Spectrom. 2003, 14, 1340-1347.

4. Little, D. P.; Speir, J. P.; Senko, M. W.; O'Connor, P. B.; McLafferty, F. W. Infrared Multiphoton Dissociation of Large Multiply Charged Ions for Biomolecule Sequencing. Anal. Chem. 1994, 66, 2809-2815.

5. Williams, E. R.; Furlong, J. J. P.; McLafferty, F. W. Efficiency of Collisionally-Activated Dissociation and 193-nm Photodissociation of Peptide Ions in Fourier Transform Mass Spectrometry. J. Am. Soc. Mass Spectrom. 1990, 1, 288-294.

6. Price, W. D.; Schnier, P. D.; Williams, E. R. Tandem Mass Spectrometry of Large Biomolecule Ions by Blackbody Infrared Radiative Dissociation. Anal. Chem. 1996, 68, 859-866.

7. Thompson, M. S.; Cui, W.; Reilly, J. P. Fragmentation of Singly Charged Peptide Ions by Photodissociation at $\lambda=157 \mathrm{~nm}$. Angew. Chem. Int. Ed. 2004, 43, 4791-4794.

8. Colorado, A.; Shen, J. X.; Vartanian, V. H.; Brodbelt, J. Use of Infrared Multiphoton Photodissociation with SWIFT for Electrospray Ionization and Laser Desorption Applications in a Quadrupole Ion Trap Mass Spectrometer. Anal. Chem. 1996, 68, 4033-4043.

9. Zubarev, R. A.; Kelleher, N. L.; McLafferty, F. W. Electron Capture Dissociation of Multiply Charged Protein Cations. A Nonergodic Process J. Am. Chem. Soc. 1998, 120, 3265-3266.

10. Kelleher, N. L.; Zubarev, R. A.; Bush, K.; Furie, B.; Furie, B. C McLafferty, F. W.; Walsh, C. T. Localization of Labile Posttranslational Modifications by Electron Capture Dissociation: The Case of $\gamma$ Carboxyglutamic Acid. Anal. Chem. 1999, 71, 4250-4253.

11. Syka, J. E. P.; Coon, J. J.; Schroeder, M. J.; Shabanowitz, J.; Hunt, D. F. Peptide and Protein Sequence Analysis by Electron Transfer Dissociation Mass Spectrometry. Proc. Natl. Acad. Sci. U.S.A. 2004, 101, 95289533.

12. Coon, J. J.; Shabanowitz, J.; Hunt, D. F.; Syka, J. E. P. Electron Transfer Dissociation of Peptide Anions. J. Am. Soc. Mass Spectrom. 2005, 16, $880-882$.

13. Sleno, L.; Volmer, D. A. Ion Activation Methods for Tandem Mass Spectrometry. J. Mass Specrom. 2004, 39, 1091-1112.

14. Washburn, M. P.; Wolters, D.; Yates, J. R. III. Large-Scale Analysis of the Yeast Proteome by Multidimensional Protein Identification Technology. Nat. Biotech. 2001, 19, 242-247.

15. Han, X.; Jin, M.; Breuker, K.; McLafferty, F. W. Extending Top-Down Mass Spectrometry to Proteins with Masses Greater Than 200 Kilodaltons. Science 2006, 314, 109-112.

16. Kebarle, P. Ion Thermochemistry and Solvation from Gas Phase Ion Equilibria. Annu. Rev. Phys. Chem. 1977, 28, 445-476.

17. Wu, R.; McMahon, T. B. Structures, Energetics, and Dynamics of Gas Phase Ions Studied by FTICR and HPMS. Mass Spectrom. Rev. 2009, 28, 546-585.

18. Price, W. D.; Schnier, P. D.; Jockusch, R. A.; Strittmatter, E. F.; Williams, E. R. Unimolecular Reaction Kinetics in the High-Pressure Limit without Collisions. J. Am. Chem. Soc. 1996, 118, 10640-10644.

19. Schnier, P. D.; Price, W. D.; Jockusch, R. A.; Williams, E. R. Blackbody Infrared Radiative Dissociation of Bradykinin and its Analogues: Energetics, Dynamics, and Evidence for Salt-Bridge Structures in the Gas Phase. J. Am. Chem. Soc. 1996, 118, 7178-7189.

20. Jockusch, R. A.; Schnier, P. D.; Price, W. D.; Strittmatter, E. F.; Demirev P. A.; Williams, E. R. Effects of Charge State on Fragmentation Pathways, Dynamics, and Activation Energies of Ubiquitin Ions Measured by Blackbody Infrared Radiative Dissociation. Anal. Chem. 1997, 69, 1119-1126.

21. Gross, D. S.; Zhao, Y.; Williams, E. R. Dissociation of Heme-Globin Complexes by Blackbody Infrared Radiative Dissociation: Molecular Specificity in the Gas Phase? J. Am. Soc. Mass Spectrom. 1997, 8, 519-524.

22. Dunbar, R. C.; McMahon, T. B. Activation of Unimolecular Reactions by Ambient Blackbody Radiation. Science 1998, 279, 194-197. 
23. Felitsyn, N.; Kitova, E. N.; Klassen, J. S. Thermal Decomposition of a Gaseous Multiprotein Complex Studied by Blackbody Infrared Radiative Dissociation. Investigating the Origin of the Asymmetric Dissociation Behavior. Anal. Chem. 2001, 73, 4647-4661.

24. Mayer, P. M.; Poon, C. The Mechanisms of Collisional Activation of Ions in Mass Spectrometry. Mass Spectrom. Rev. 2009, 4, 608-639.

25. Marzluff, E. M.; Campbell, S.; Rodgers, M. T.; Beauchamp, J. L. Collisional Activation of Large Molecules Is an Efficient Process. J. Am. Chem. Soc. 1994, 116, 6947-6948.

26. Armentrout, P. B. Kinetic Energy Dependence of Ion-Molecule Reactions: Guided Ion Beams and Threshold Measurements. Int. J. Mass Spectrom. 2000, 200, 219-241.

27. Muntean, F.; Heumann, L.; Armentrout, P. B. Modeling Kinetic Shifts in Threshold Collision-Induced Dissociation. Case Study: Dichlorobenzene Cation Dissociation. J. Chem. Phys. 2002, 116, 5593-5602.

28. Vékey, K. Internal Energy Effects in Mass Spectrometry. J. Mass Spectrom. 1996, 31, 445-463.

29. Lifshitz, C. Kinetic Shifts. Eur. J. Mass Spectrom. 2002, 8, 85-92.

30. Laskin, J. Energetics and Dynamics of Fragmentation of Protonated Leucine Enkephalin from Time- and Energy-Resolved Surface-Induced Dissociation Studies. J. Phys. Chem. A 2006, 110, 8554-8562.

31. Laskin, J.; Bailey, T. H.; Futrell, J. H. Shattering of Peptide Ions on Self-Assembled Monolayer Surfaces. J. Am. Chem. Soc. 2003, 125, 16251632.

32. Laskin, J.; Futrell, J. Internal Energy Distributions Resulting from Sustained Off-Resonance Excitation in Fourier Transform Ion Cyclotron Resonance Mass Spectrometry. II. Fragmentation of the 1-Bromonaphthalene Radical Cation. J. Phys. Chem. A 2000, 104, 5484-5494.

33. Laskin, J.; Byrd, M.; Futrell, J. Internal Energy Distributions Resulting from Sustained Off-Resonance Excitation in FTMS. I. Fragmentation of the Bromobenzene Radical Cation. Int. J. Mass Spectrom. 2000, 195/196, 285-302

34. Griffiths, I. W.; Harris, F. M.; Mukhtar, E. S.; Beynon, J. H. Calculation of the Abundance Ratio $\left[91^{+} / 92^{+}\right]$from $n$-Butylbenzene Molecular-Ions as a Function of Internal Energy. Int. J. Mass Spectrom. Ion Processes 1981, $41,83-88$.

35. Chen, J. H.; Hays, J. D.; Dunbar, R. C. Competitive Two-Channel Photodissociation of $n$-Butylbenzene Ions in the Fourier-Transform Ion Cyclotron Resonance Mass Spectrometer. J. Phys. Chem. 1984, 88, 4759-4764.

36. Baer, T.; Dutuit, O.; Mestdagh, H.; Rolando, C. Dissociation Dynamics of $n$-Butylbenzene Ions: The Competitive Production of $m / z 91$ and 92 Fragment Ions. J. Phys. Chem. 1988, 92, 5674-5679.

37. Wysocki, V. H.; Kenttämaa, H. I.; Cooks, R. G. Internal Energy Distributions of Isolated Ions After Activation by Various Methods. Int. J. Mass Spectrom. Ion Processes 1987, 75, 181-208.

38. Dekrey, M. J.; Kenttämaa, H. I.; Wysocki, V. H.; Cooks, R. G. Energy Deposition in $\left[\mathrm{Fe}(\mathrm{CO})_{5}\right]^{+}$. Upon Collision with a Metal-Surface. Org. Mass Spectrom. 1986, 21, 193-195.

39. Leib, R. D.; Donald, W. A.; Bush, M. F.; O'Brien, J. T.; Williams, E. R. Internal Energy Deposition in Electron Capture Dissociation Measured Using Hydrated Divalent Metal Ions as Nanocalorimeters. J. Am. Chem. Soc. 2007, 129, 4894-4895

40. Leib, R. D.; Donald, W. A.; Bush, M. F.; O’Brien, J. T.; Williams, E. R. Nonergodicity in Electron Capture Dissociation Investigated Using Hydrated Ion Nanocalorimetry. J. Am. Soc. Mass Spectrom. 2007, 18, 1217-1231.

41. Leib, R. D.; Donald, W. A.; O’Brien, J. T.; Bush, M. F.; Williams, E. R. Reduction Energies of $1 \mathrm{M}$ Aqueous Ruthenium(III) Hexa-Amine in the Gas Phase: A Route Towards Establishing an Absolute Electrochemical Scale. I. Am. Chem. Soc. 2007, 129, 7716-7717.

42. Donald, W. A.; Leib, R. D.; O'Brien, J. T.; Williams, E. R. Directly Relating Gas-Phase Cluster Measurements to Solution-Phase Hydrolysis, the Absolute Standard Hydrogen Electrode Potential, and the Absolute Proton Solvation Energy. Chem. Eur. J. 2009, 15, 5926-5934.

43. Donald, W. A.; Leib, R. D.; Demireva, M.; O’Brien, J. T.; Prell, J. S.; Williams, E. R. Directly Relating Reduction Energies of Gaseous $\mathrm{Eu}\left(\mathrm{H}_{2} \mathrm{O}\right)_{n}{ }^{3+}, n=55-140$, to Aqueous Solutions: The Absolute SHE Potential and Real Proton Solvation Energy. J. Am. Chem. Soc. 2009, 131, 13328-13337.

44. Donald, W. A.; Leib, R. D.; O’Brien, J. T.; Bush, M. F.; Williams, E. R. Absolute Standard Hydrogen Electrode Potential Measured by Reduction of Aqueous Nanodrops in the Gas Phase. J. Am. Chem. Soc. 2008, 130, 3371-3381.
45. Donald, W. A.; Leib, R. D.; O’Brien, J. T.; Holm, A. I. S.; Williams, E. R. Nanocalorimetry in Mass Spectrometry: A Route to Understanding Ion and Electron Solvation. Proc. Natl. Acad. Sci. U.S.A. 2008, 105, 1810218107.

46. Holm, A. I. S.; Donald, W. A.; Hvelplund, P.; Larsen, M. K.; Nielsen, S. B.; Williams, E. R. Investigation of Energy Deposited by Femtosecond Electron Transfer in Collisions Using Hydrated Ion Nanocalorimetry. J. Phys. Chem. A 2008, 112, 10721-10727.

47. Prell, J. S.; O’Brien, J. T.; Holm, A. I. S.; Leib, R. D.; Donald, W. A.; Williams, E. R. Electron Capture by a Hydrated Gaseous Peptide: Effects of Water on Fragmentation and Molecular Survival. J. Am. Chem. Soc. 2008, 130, 12680-12689.

48. Donald, W. A.; Williams, E. R. Measuring the Extent and Width of Internal Energy Deposition in Ion Activation Using Nanocalorimetry. J. Am. Soc. Mass Spectrom. 2009; DOI:10.1016/j.jasms.2009.12.006.

49. Wong, R. L.; Paech, K.; Williams, E. R. Blackbody Infrared Radiative Dissociation at Low Temperature: Hydration of $\mathrm{X}^{2+}\left(\mathrm{H}_{2} \mathrm{O}\right)_{n}$, for $\mathrm{X}=\mathrm{Mg}$, Ca. Int. J. Mass Spectrom. 2004, 232, 59-66.

50. Remes, P. M. Instrumentation and Methods for the Characterization of Ion Structure and Internal Energy in the Gas Phase; Ph.D. Dissertation, University of North Carolina, Chapel Hill, NC, 2007.

51. Demireva, M. P.; Remes, P. M.; Glish, G. L. Internal Energy Relaxation of Different Mass Peptide Ions in Quadrupole Ion Trap Mass Spectrometry. MP098. Proceedings of the 55th ASMS Conference on Mass Spectrometry and Allied Topics; Indianapolis, IN, June, 2007.

52. Baer, T.; Mayer, P. M. Statistical Rice-Ramsperger-Kassel-Marcus QuasiEquilibrium Theory Calculations in Mass Spectrometry. J. Am. Soc. Mass Spectrom. 1997, 8, 103-115.

53. Vachet, R. W.; Bishop, B. M.; Ericson, B. W.; Glish, G. L. Novel Peptide Dissociation: Gas-Phase Intramolecular Rearrangement of Internal Amino Acid Residues. J. Am. Chem. Soc. 1997, 119, 5481-5488.

54. Asano, K. G.; Goeringer, D. E.; Butcher, D. J.; McLuckey, S. A. Bath Gas Temperature and the Appearance of Ion Trap Tandem Mass Spectra of High-Mass Ions. Int. J. Mass Spectrom. 1999, 190/191, 281-293.

55. Džidić, I.; Kebarle, P. Hydration of the Alkali Ions in the Gas Phase. Enthalpies and Entropies of Reactions $\mathrm{M}^{+}\left(\mathrm{H}_{2} \mathrm{O}\right)_{n-1}+\mathrm{H}_{2} \mathrm{O}=$ $\mathrm{M}^{+}\left(\mathrm{H}_{2} \mathrm{O}\right)_{n}$. J. Phys. Chem. 1970, 74, 1466-1474.

56. Donald, W. A.; Williams, E. R. Evaluation of Different Implementations of the Thomson Liquid Drop Model: Comparison to Monovalent and Divalent Cluster Ion Experimental Data. J. Phys. Chem. A 2008, 112, 3515-3522.

57. Schnier, P. D.; Price, W. D.; Strittmatter, E. F.; Williams, E. R. Dissociation Energetics and Mechanisms of Leucine Enkephalin $(\mathrm{M}+\mathrm{H})^{+}$and $(2 \mathrm{M}+\mathrm{X})^{+}$Ions $(\mathrm{X}=\mathrm{H}, \mathrm{Li}, \mathrm{Na}, \mathrm{K}$, and $\mathrm{Rb})$ Measured by Blackbody Infrared Radiative Dissociation. J. Am. Soc. Mass Spectrom. 1997, 8 , 771-780.

58. Nacson, S.; Harrison, A. G. Energy Transfer in Collisional Activation Energy Dependence of the Fragmentation of $n$-Alkylbenzene Molecular Ions. Int. J. Mass Spectrom. Ion Processes 1985, 63, 325-337.

59. Wu, L.; Denault, J. W.; Cooks, R. G.; Drahos, L.; Vékey, K. Alkal Chloride Cluster Ion Dissociation Examined by the Kinetic Method: Heterolytic Bond Dissociation Energies, Effective Temperatures, and Entropic Effects. J. Am. Soc. Mass Spectrom. 2002, 13, 1388-1395.

60. Yamaoka, H.; Dong, P.; Durup, J. Energetics of the Collision-Induced Dissociations $\mathrm{C}_{2} \mathrm{H}_{2}^{+} \rightarrow \mathrm{C}_{2} \mathrm{H}^{+}+\mathrm{H}$ and $\mathrm{C}_{2} \mathrm{H}_{2}^{+} \rightarrow \mathrm{H}^{+}+\mathrm{C}_{2} \mathrm{H}$. J. Chem. Phys. 1969, 51, 3465-3476.

61. Muntean, F.; Armentrout, P. B. Guided Ion Beam Study of CollisionInduced Dissociation Dynamics: Integral and Differential Cross Sections. J. Chem. Phys. 2001, 115, 1213-1228.

62. Schnier, P. D.; Jurchen, J. C.; Williams, E. R. The Effective Temperature of Peptide Ions Dissociated by Sustained Off-Resonance Irradiation Collisional Activation in Fourier Transform Mass Spectrometry. J. Phys. Chem. B 1999, 103, 737-745.

63. Vachet, R. W.; Ray, K. L.; Glish, G. L. Origin of Product Ions in the MS/MS Spectra of Peptides in a Quadrupole Ion Trap. J. Am. Soc. Mass Spectrom. 1998, 9, 341-344.

64. Moet-Ner (Mautner), M.; Dongré, A. R.; Somogyi,. Á.; Wysocki, V. H. Thermal Decomposition Kinetics of Protonated Peptides and Peptide Dimers, and Comparison with Surface Induced Dissociation. Rapid Commun. Mass Spectrom. 1995, 9, 829-836.

65. Asano, K. G.; Goeringer, D. E.; McLuckey, S. A. Thermal Dissociation in the Quadrupole Ion Trap: Ions Derived from Leucine Enkephalin. Int. J. Mass Spectrom. 1999, 185/186/187, 207-219. 